\title{
How are we currently training and maintaining clinical readiness of US and UK military surgeons responsible for managing head, face and neck wounds on deployment?
}

\author{
John Breeze, ${ }^{1,2}$ J G Combes, ${ }^{3}$ J DuBose, ${ }^{4}$ D B Powers ${ }^{2}$
}

\begin{abstract}
${ }^{1}$ Academic Department of Military Surgery and Trauma, Royal Centre for Defence Medicine, Birmingham, UK ${ }^{2}$ Division of Plastic, Maxillofacial, and Oral Surgery, Duke University Medical Center, Durham, North Carolina, USA ${ }^{3}$ Department of Oral and Maxillofacial Surgery, Royal Surrey County Hospital, Guildford, UK

${ }^{4}$ C-STARS (Center for the Sustainment of Trauma and Readiness Skills), R Adams Cowley Shock Trauma Center, Baltimore, Maryland, USA
\end{abstract}

\section{Correspondence to}

John Breeze, Division of Plastic, Reconstructive, Maxillofacial \& Oral Surgery, Duke University Medical Center, Durham, NC 27705, USA; editor.jramc@ bmj.com

Received 16 April 2018 Accepted 22 April 2018
Check for updates

To cite: Breeze J, Combes JG,
DuBose J, et al.
J R Army Med Corps
2018;164:183-185.

\begin{abstract}
Introduction The conflicts in Iraq and Afghanistan provided military surgeons from the USA and the UK with extensive experience into the management of injuries to the head, face and neck (HFN) from high energy bullets and explosive weaponry. The challenge is now to maintain the expertise in managing such injuries for future military deployments.
\end{abstract}

Methods The manner in which each country approaches four parameters required for a surgeon to competently treat HFN wounds in deployed military environments was compared. These comprised initial surgical training (residency/registrar training), surgical fellowships, hospital type and appointment as an attending (USA) or consultant (UK) and predeployment training.

Results Neither country has residents/registrars undertaking surgical training that is military specific. The Major Trauma and Reconstructive Fellowship based in Birmingham UK and the Craniomaxillofacial Trauma fellowship at Duke University USA provide additional training directly applicable to managing HFN trauma on deployment. Placement in level 1 trauma/major trauma centres is encouraged by both countries but is not mandatory. US surgeons attend one of three single-service predeployment courses, of which HFN skills are taught on both cadavers and in a 1-week clinical placement in a level 1 trauma centre. UK surgeons attend the Military Operational Surgical Training programme, a 1-week course that includes 1 day dedicated to teaching HFN injury management on cadavers.

Conclusions Multiple specialties of surgeon seen in the civilian environment are unlikely to be present, necessitating development of extended competencies. Military-tailored fellowships are capable of generating most of these skills early in a career. Regular training courses including simulation are required to maintain such skills and should not be given only immediately prior to deployment. Strong evidence exists that military consultants and attendings should only work at level 1 /major trauma centres.

\section{INTRODUCTION}

The conflicts in Iraq and Afghanistan provided military surgeons from the USA and the UK with extensive experience into the management of injuries to the head, face and neck (HFN) from high energy bullets and explosive weaponry. ${ }^{1-13}$ Surgeons treating such injuries included neurosurgeons, plastic surgeons (PRS), vascular surgeons, oral and

\section{Key messages}

- Specific skill sets are required to provide optimal treatment of head, face and neck (HFN) wounds in the deployed military environment.

- Such skills sets are currently beyond the remit of a single surgical specialty, necessitating the deployment of specific combinations of surgeons and/or additional training.

- Currently, neither the USA or UK has residents or registrars undertaking surgical training that is specific to treating military HFN wounds.

- Military tailored fellowships are the most practical manner by which skills necessary for optimising treatment of HFN wounds on deployment are first consolidated.

- Placement as an attending or consultant in a level 1 trauma or major trauma centre should be strongly encouraged.

- Regular training courses including simulation are required to maintain such skills and should not be given only immediately prior to deployment.

maxillofacial surgeons (OMFSs), otorhinolaryngologists (OTO), ophthalmologists and general surgeons. ${ }^{23}$ It was widely recognised by both countries that a single specialty of surgeon could not manage all of these types of injuries. Multidisciplinary teams similar to that seen in civilian level 1 trauma centres in the USA or major trauma centres (MTCs) in the UK with all these specialties present was the ideal strived for. ${ }^{14}$ However, in practice, this almost never occurred for either country, and instead a small group of two or three surgeons with HFN skills generally worked together. ${ }^{15}$ For example, the UK experience in Iraq and Afghanistan was that two surgical specialties were usually present, such as OMFS combined with neurosurgeons (Kandahar) or PRS with general surgeons (Camp Bastion). ${ }^{2}$ The USA preferentially deployed as an HFN trauma team with neurosurgeons coupled with OMFS, ophthalmology and OTO specialists (Balad and Baghdad) and circumstances where isolated HFN specialists practised solo, such as OTO and PRS (Bagram), with or without immediate neurosurgical support. ${ }^{16}$

The ability for the Armed Forces to deploy surgeons capable of competently treating HFN 
wounds is based on a number of parameters. These include initial training following medical school (residency/registrar training), post-training fellowships, attending/consultant job plan (ie, their daily clinical exposure) and predeployment training. During their deployments to the conflicts in Iraq and Afghanistan, many surgeons, particularly those in the UK, were of a generation that had undergone broader surgical training than the more streamlined, and narrowed, pathway that occurs today. Predeployment training was then given to develop extended competencies to either teach or renew skills not within their normal civilian surgical practice. The result of this was the production of a generation of surgeons who had been broadly trained and had gained extensive knowledge in the treatment of military injuries. ${ }^{17}$ However, within years, many have now retired from the military, and the challenge is now to train and maintain the clinical readiness of a new generation of surgeons capable of managing HFN wounds. The aim of this paper is to compare and contrast the manner in which the USA and UK are now training and maintaining such surgeons and identify potential avenues for the future.

\section{METHOD}

A subjective analysis was undertaken to compare the manner in which the Armed Forces of the USA and UK approach the following four parameters required for a surgeon to competently treat HFN wounds in the deployed military environment.

- Initial surgical training (residency/registrar training).

- Fellowships.

- Attending (USA)/consultant (UK) job plan and location.

- Predeployment training.

\section{RESULTS}

\section{Initial surgical training}

Military surgical trainees in both the USA and UK undergo between 5 years and 6 years of specialist surgical training. The exception is OMFS, for which in the UK, and also for a proportion of US trainees, requires dual degrees (medicine and dentistry) necessitating an additional 3-4 years of training. Neither country has residents/registrars undertaking training at this stage that is military specific. Clinical exposure to injury mechanisms similar to that seen in wartime is to a degree determined by the location of some training establishments. ${ }^{17}$

\section{Fellowships}

No specific military fellowships applicable to gaining HFN skills exist for either country. Craniofacial fellowships may provide confidence (but not necessarily competence) in intracranial access. ${ }^{18}$ The Major Trauma and Reconstruction Fellowship based at the Queen Elizabeth Hospital Birmingham, UK, at the military Role 4 medical treatment facility provides multidisciplinary experience in complex trauma reconstruction, with a strong emphasis on HFN injuries. ${ }^{19}$ Fellows are given exposure to operating lists and clinics of all surgical specialties treating HFN trauma and are regularly expected to lead the major trauma team in the emergency room. The craniomaxillofacial trauma fellowship at Duke University Medical Centre was started in 2018 and is the first in the USA and UK to specifically focus on the treatment and sequential reconstruction of ballistic injuries to the HFN regions.

\section{Attending/consultant job plan and location}

Placement in level 1 trauma/MTCs is encouraged by both countries but is not mandatory. No particular types of clinical activity are mandated, but it is unusual for any surgeons not to have some component of trauma within their job plan. Clinical exposure varies as to the size and location of the hospital, with US level 1 trauma centres experiencing far higher levels of gunshot wounds than in their UK equivalents.

\section{Predeployment training}

Each nation has developed its own unique course in which skills to treat HFN injuries on deployed operations are taught. US surgical training is service specific, with the Army attending a 2-week programme at the University of Miami/Ryder Trauma Center and the Navy at the University of Southern California/ Los Angeles County Medical Center. ${ }^{20-22}$ The US Air Force has three centres for the Sustainment of Trauma and Readiness Skills (C-STARS), comprising the R. Adams Cowley Shock Trauma Center at the University of Maryland (C-STARS Baltimore), Saint Louis University (C-STARS St. Louis) and The University Hospital/University of Cincinnati (C-STARS Cincinnati). ${ }^{20}$ The US courses are similar in that they have classroom and cadaveric training, as well as a 1-week clinical attachment to the level 1 trauma centre, but the US Air Force programmes differ markedly in their focus based on locations. The C-STARS Baltimore programme focuses on surgical care providers, critical care nursing and anaesthesia, combat medic and surgical technician training. The C-STARS Cincinnati location is primarily centred towards aeromedical evacuation, while the St. Louis location is directed towards currency training of Air Force Reserve and Air National Guard providers. ${ }^{20}$ UK surgeons attend the Military Operational Surgical Training (MOST) programme, a 1-week classroom and cadaveric course that includes 1 day dedicated to HFN injuries. Skills taught in these programmes include decompressive craniotomy, facial fracture stabilisation, surgical airways, lateral canthotomy and cervical haemorrhage control. US courses in addition teach facial fracture fixation, but this is not taught on the MOST course. This reflects a difference in teaching between countries, with US Ear Nose and Throat (ENT) and OMFS performing open reduction and internal fixation in some cases on US service personnel in Iraq prior to evacuation. $^{1313}$ In contrast, UK OMFSs in Afghanistan performed delayed fixation for high-energy transfer wounds once tissue viability was known, by which point UK service personnel had inevitably been evacuated. ${ }^{2} 12$ Instead UK service personnel with facial fractures were stabilised with intermaxillary or external fixation, in conjunction with a surgical airway if required. All UK military surgeons attend two predeployment hospital exercises in a purpose-built hospital simulation facility, ${ }^{9}$ including a 'whole hospital' exercise over a 48-hour period, using simulated casualties with wounds depicting current injury patterns seen on deployment.

\section{DISCUSSION}

Huge organisational, logistical and financial challenges face our two nations as they seek to maintain the lessons learnt from recent conflicts and train future generations of military surgeons responsible for treating HFN injuries. The skill sets believed to be required for UK surgeons to adequately manage high energy transfer injuries to the HFN in the deployed military environment are now well established. ${ }^{14}$ Multiple specialties of surgeon seen in the civilian environment are unlikely to be present, necessitating the development of extended competencies. It is proposed that tailored training programmes specifically for military residents be developed early in their career. The most logical method for this would be a military-tailored fellowships focusing 
on the complex management of high energy transfer injuries to the HFN region.

Comparisons between those HFN injury management skills taught on both US and UK predeployment courses demonstrate that they are generally relatively similar. However good a course may be though, it is no substitute for regular clinical experience. This maintains the surgical skills required and enables clinicians to regular practice decision making in a multidisciplinary environment. Strong evidence exists that military consultants and attendings should only work at level 1/MTCs. If this is not practically possible, then surgeons responsible for treating HFN injuries may potentially refresh their skills during dedicated placements at such hospitals prior to deployment. Civilian military collaboration at level $1 /$ MTCs will also be essential in the future to gain sufficient patient numbers and injury severity for effective clinical military research. ${ }^{23}$

Training with those colleagues (both surgical and non-surgical) that you will deploy with has been shown to improve patient outcomes, often through improved communication. Logistically, this can be highly difficult to achieve when clinicians are often geographically far apart. Virtual simulation can address these issues to a degree, but every effort should be made to try to enable these clinicians to train together. Instead of meeting together as individual surgical specialties, the UK is currently developing a yearly multispecialty meeting for those surgeons responsible for treating HFN wounds on deployment, which is planned to include simulation. This meeting aims to produce a 'head and neck cadre', from which a smaller number, but complementary pool of surgeons, from different specialties can deploy but between them still have comparable skills to a larger group. These should include both regular as well as reservist officers. This meeting should be extended to our other allies of the North Atlantic Treaty Organization (NATO), recognising that both in Iraq and Afghanistan, the deployed hospitals had surgeons from a number of countries who were often unaware of the capabilities of one another.

\section{CONCLUSIONS}

The skill sets required to adequately manage high energy transfer injuries to the HFN in the deployed military environment are now well established. Multiple specialties of surgeon seen in the civilian environment are unlikely to be present, necessitating the development of extended competencies. Military-tailored fellowships are capable of generating most of these skills early in a career. Regular training courses and simulation are required to maintain such skills and should not be given only immediately prior to deployment. Strong evidence exists that military consultants and attendings should only work at level 1/MTCs. If this is not practically possible, then surgeons responsible for treating HFN injuries may potentially refresh their skills during dedicated placements at such hospitals prior to deployment.

Contributors Planning: JB and DP. Conducting: JB, DBP and JD. Reporting: all authors.

Funding The authors have not declared a specific grant for this research from any funding agency in the public, commercial or not-for-profit sectors.

Competing interests None declared.
Patient consent Not required.

Provenance and peer review Not commissioned; internally peer reviewed.

(C) Article author(s) (or their employer(s) unless otherwise stated in the text of the article) 2018. All rights reserved. No commercial use is permitted unless otherwise expressly granted.

\section{REFERENCES}

1 Keller MW, Han PP, Galarneau MR, et al. Characteristics of maxillofacial injuries and safety of in-theater facial fracture repair in severe combat trauma. Mil Med 2015;180:315-20.

2 Gibbons AJ, Mackenzie N. Lessons learned in oral and maxillofacial surgery from British military deployments in Afghanistan. J R Army Med Corps 2010;156:113-6.

3 Powers DB. Distribution of civilian and military maxillofacial surgical procedures performed in an Air Force theatre hospital: implications for training and readiness. $J R$ Army Med Corps 2010;156:117-21.

4 Wordsworth M, Thomas R, Breeze J, et al. The surgical management of facial trauma in British soldiers during combat operations in Afghanistan. Injury 2017;48:70-4.

5 Breeze J, Monaghan AM, Williams MD, et al. Five months of surgery in the multinational field hospital in Afghanistan with an emphasis on oral and maxillofacial injuries. J R Army Med Corps 2010;156:125-8.

6 Breeze J, Gibbons AJ, Combes JG, et al. Oral and maxillofacial surgical contribution to 21 months of operating theatre activity in Kandahar Field Hospital: 1 February 200731 October 2008. Br J Oral Maxillofac Surg 2011:49:464-8.

7 Brennan J. Experience of first deployed otolaryngology team in Operation Iraqi Freedom: the changing face of combat injuries. Otolaryngol Head Neck Surg 2006;134:100-5

8 Feldt BA, Salinas NL, Rasmussen TE, et al. The joint facial and invasive neck trauma (J-FAINT) project, Iraq and Afghanistan 2003-2011. Otolaryngol Head Neck Surg 2013;148:403-8.

9 Brisebois RJ, Tien HC. Surgical experience at the Canadian-led Role 3 Multinational Medical Unit in Kandahar, Afghanistan. J Trauma 2011;71:S397-S400.

10 Breeze J, Gibbons AJ, Opie NJ, et al. Maxillofacial injuries in military personnel treated at the Royal Centre for Defence Medicine June 2001 to December 2007. Br J Oral Maxillofac Surg 2010;48:613-6.

11 Breeze J, McVeigh K, Lee JJ, et al. Management of maxillofacial wounds sustained by British service personnel in Afghanistan. Int J Oral Maxillofac Surg 2011;40:483-6.

12 Breeze J, Gibbons AJ, Hunt NC, et al. Mandibular fractures in British military personnel secondary to blast trauma sustained in Iraq and Afghanistan. Br J Oral Maxillofac Surg 2011;49:607-11.

13 Zachar MR, Labella C, Kittle CP, et al. Characterization of mandibular fractures incurred from battle injuries in Iraq and Afghanistan from 2001-2010. J Oral Maxillofac Surg 2013;71:734-42.

14 Breeze J, Blanch R, Baden J, et al. Skill sets required for the management of military head, face and neck trauma: a multidisciplinary consensus statement. J R Army Med Corps 2018. doi: 10.1136/jramc-2017-000881. [Epub ahead of print].

15 Rosenfeld JV. How will we produce the next generation of military surgeons? Re: Skill sets and competencies for the modern military surgeon: lessons from UK military operations in Southern Afghanistan. Injury 2010;41:435-6.

16 Cho RI, Bakken HE, Reynolds ME, et al. Concomitant cranial and ocular combat injuries during Operation Iraqi Freedom. J Trauma 2009;67:516-20.

17 Ramasamy A, Hinsley DE, Edwards DS, et al. Skill sets and competencies for the modern military surgeon: lessons from UK military operations in Southern Afghanistan. Injury 2010;41:453-9.

18 Gibbons AJ, Monaghan AM, Dhariwal DK, et al. A fellowship in craniofacial surgery. J R Army Med Corps 2006;152:89-90.

19 Hammond D, Breeze J, Evriviades D. The Reconstructive Trauma Surgery Interface Fellowship and its applicability to military and civilian trainees. Accepted for publication JRAMC.

20 Thorson CM, Dubose JJ, Rhee P, et al. Military trauma training at civilian centers. J Trauma Acute Care Surg 2012;73:S483-S489.

21 DuBose J, Rodriguez C, Martin M, et al. Preparing the surgeon for war. J Trauma Acute Care Surg 2012;73:S423-S430.

22 Hight RA, Salcedo ES, Martin SP, et al. Level I academic trauma center integration as a model for sustaining combat surgical skills. J Trauma Acute Care Surg 2015;78:1176-81.

23 Stinner DJ, Wenke JC, Ficke JR, et al. Major Extremity Trauma Research Consortium (METRC). Military and Civilian Collaboration: The Power of Numbers. Mil Med 2017;182(S1):10-17. 